\title{
Correction to: Molecular characterisation of acanthocephalans from Australian marine teleosts: proposal of a new family, synonymy of another and transfer of taxa between orders
}

\author{
Daniel C. Huston $(\mathbb{D} \cdot$ Thomas H. Cribb $\mathbb{1} \cdot$ Lesley R. Smales $\mathbb{( 1}$
}

Published online: 25 August 2020

(C) Springer Nature B.V. 2020

Correction to: Syst Parasitol (2020) 97:1-23

https://doi.org/10.1007/s11230-019-09896-2

Shortly after publication it was brought to authors' attention that two of the cox 1 sequences reported in the study, those of Neoechinorhynchus tylosuri (MN692675) and Transvena annulospinosa (MN692690) were potentially erroneous. After investigation, it was determined that this was indeed the case and was caused by contamination of original sequencing results. They were found to be nearduplicates of other species from the same sequencing

The original article can be found online at https:// doi.org/10.1007/s11230-019-09896-2.

\section{C. Huston ( $\square)$}

Institute for Marine and Antarctic Studies, The University of Tasmania, Hobart, TAS 7001, Australia

e-mail: Daniel.Huston@uqconnect.edu.au

\section{T. H. Cribb}

School of Biological Sciences, The University of Queensland, St. Lucia, QLD 4072, Australia

\section{R. Smales}

Parasitology Section, South Australian Museum, Adelaide, SA 5000, Australia batch. These sequences have been removed from GenBank. Unfortunately, this means that no $\operatorname{cox} 1$ sequence data were provided for the above two species in the referenced study. The remaining $\operatorname{cox} 1$ sequences reported have been checked and are reliable. Furthermore, $\operatorname{cox} 1$ sequence data were not analysed as part of the study, and thus the above error does not affect the results or conclusions of the study. Corrections to the text in reference to the above are made in Table 1 (removal of the above GenBank accession numbers), on page 10 ("Sequence data for all three targeted markers were obtained for $\mathbf{1 3}$ (rather than 15) of the 17 acanthocephalan species studied") and on page 19 ("We generated new coxl sequence data for all but three (rather than one) of the acanthocephalan species from our collection...”).

Two unrelated typographical errors were also found. The new family name 'Pyriproboscidae' was misspelled in the last line of the abstract, and in the first line of the introduction it should read "some 1,200 species" rather than 12,000 .

The authors thank Dr Andrés Martínez-Aquino for bringing the issues with the sequences to their attention and apologise to all for any inconvenience the above errors may have caused.

The corrected Table 1 is provided below. 


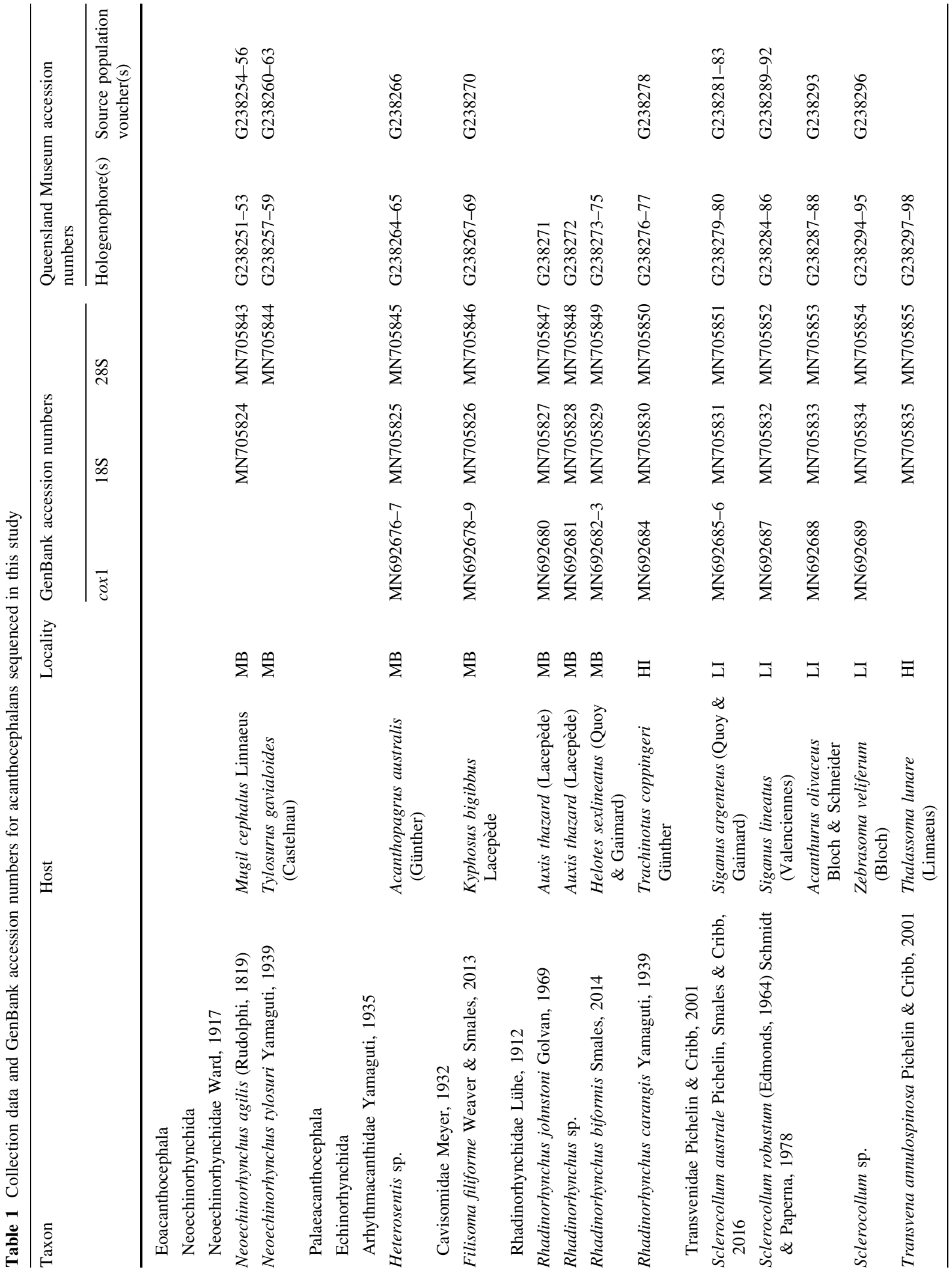




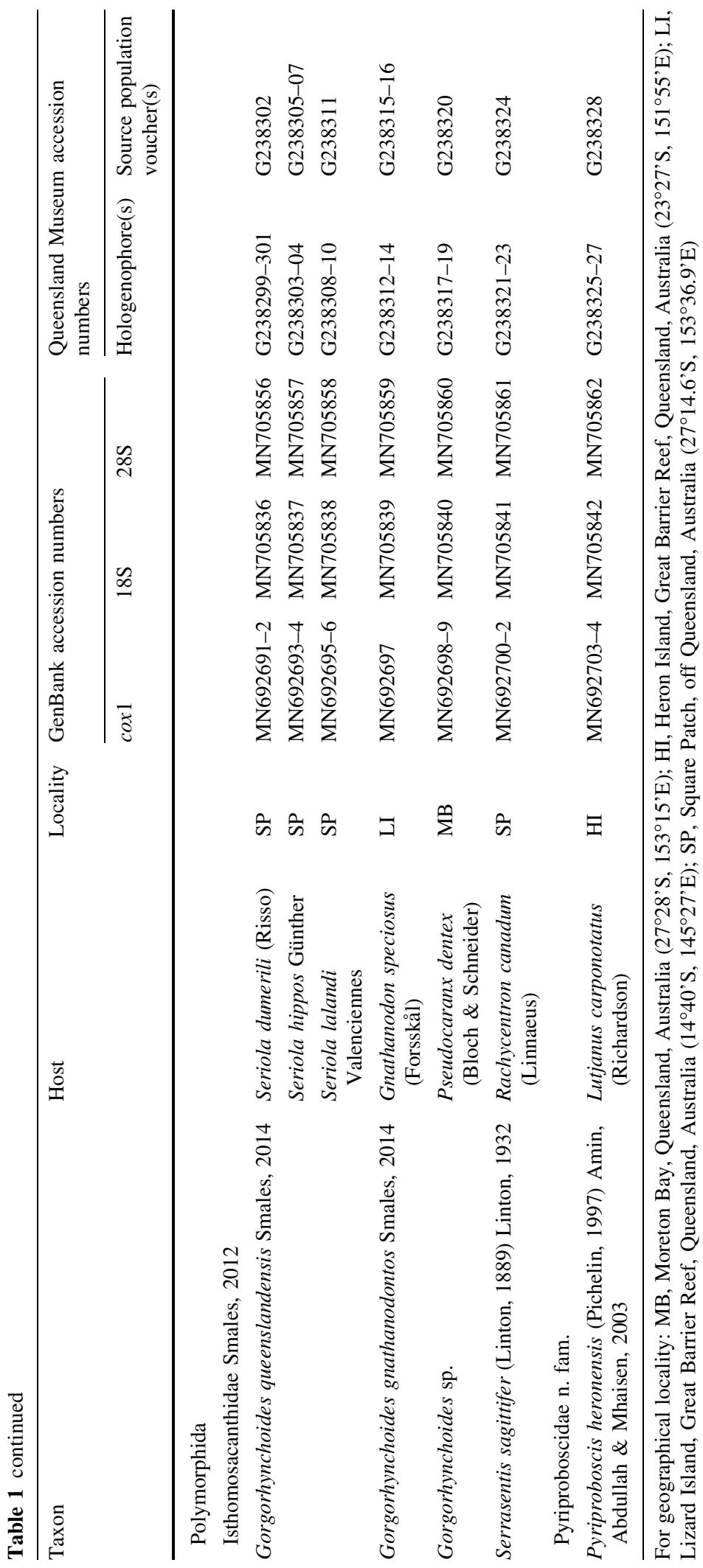

